\title{
FROM THE EDITOR.....
}

It is indeed a coincidence that the editorial theme for this issue is shared with the previous issue. Anyhow, considering the significance and impact of the theme 'Sustainable Energy' its importance cannot be over emphasized.

When considering sustainable energy, well-tried and dependable Hydro Power option cannot escape consideration. However, other options for power generation could be even more eco-friendly, though on the side of dependability they do not rate that high. Though Solar energy, Wave energy, and Wind energy fall in to this category, Wind had come forward as a more reliable, and economically better option.

Though Sri Lanka is not in a position to boast about wind power potential, southeastern zone of the island receives substantial amount of wind flow over the clear expanses of sea. Therefore, the location of the pilot Wind Power project is technically appropriate on the above reason coupled with availability of large clear land spaces with lesser windbreaks.

If the capital expenditure for such a project could be recovered in as Httle as ten years with a projected life span of at least ten more years, this definitely is an energy option for serious consideration and implementation in Sri Lanka.

Eng. (Dr.) T. M. Pallewatta, Int PEng (SL), C.Eng, FIE (SL)

Editor, 'ENGINEER', Journal of The Institution of Engineers.

Editor, Technical Papers for the Transactions of The Institution of Engineers, 